\title{
Neuroenteric cyst of the left lateral ventricle: case report and review of the literature
}

\author{
Xiaoyang Ling ${ }^{1 \dagger}$, Shaofeng Yang ${ }^{2 \dagger}$, Zhengxiang Luo ${ }^{1}$, Wenbing Zhang ${ }^{1}$, Yansong Zhang ${ }^{1}$ and Penglai Zhao ${ }^{1,3^{*}}$
}

\begin{abstract}
Background: Intracranial supratentorial neuroenteric cysts are very rare lesions in the central nervous system. We described a neuroenteric cyst of the left lateral ventricle in a 38-year old male, which had been confirmed by using immunohistochemistry. To date,this was the first reported case in which the neuroenteric cyst was located in the lateral ventricle.

Case presentation: The patient had paroxysmal headache for half a year which exacerbated in the recent two months. MRI showed a $3 \mathrm{~cm}^{*} 3 \mathrm{~cm}^{*} 2.5 \mathrm{~cm}$ cyst in the left lateral ventricle. We reported the first case, where the NC in the lateral ventricle was partly resected, provided new evidence to develop the hypothesis on NC etiology. The cyst was left partly due to the strong adherence to the surrounding structures. The final diagnosis was confirmed on histopathological and immunohistochemical analysis of the cyst.

Conclusion: Lacking in characterization of the specific imaging features, neuroenteric cyst may be misdiagnosed as other types of cysts preoperatively. At present, surgical excision is the only effective treatment for neuroenteric cysts. Early diagnosis and more treatment options may be available in the future with more cases of neuroenteric cyst being reported and its pathogenesis being understood further. we hope the first reporting of the lateral ventricle NC by now can provide new evidence to NC etiology.
\end{abstract}

Keywords: Intracranial, Supratentorial, Neuroenteric cyst, Lateral ventricle

\section{Background}

Neuroenteric cyst (NC), also known as enterogenous cyst, has been defined as "a cyst lined by mucinsecreting epithelium resembling that of the gastrointestinal tract", according to the World Health Organization Classification of the Central Nervous System Tumors [1]. NCs are usually located in the ventral spinal cord of cervicothoracic segements [2-7]. They are rarely found in the intracranial compartment where the cysts develop usually along the midline in the posterior cranial fossa, anterior to the brainstem or in the fourth ventricle according to the cases reported [8]. However, there had

\footnotetext{
* Correspondence: 13382760868@163.com

${ }^{\dagger}$ Equal contributors

'Department of Neurosurgery, Nanjing Brain Hospital Affiliated to Nanjing Medical University, Nanjing 210029, China

${ }^{3}$ Department of Neurosurgery, Lishui Peoples's Hospital, Nanjing 211200, China

Full list of author information is available at the end of the article
}

been only 21 NCs cases up to 2016 in the supratentorial area [9], which has attracted our attention, because the patho-embryology of supratentorial NCs remains entirely unknown and thus there might be a considerably huge diagnostic challenge [2]. We recently found a case of NCs in the left lateral ventricle where the NCs have never been reported before. Details of this case and operation followed had been described. Besides, we reviewed the literatures to discuss the clinical presentation, radiological imaging, histopathological and surgical characteristics of NCs.

\section{Case presentation}

Clinical presentation and imaging of NCs

A 38-year-old man had paroxysmal headache for half a year which exacerbated in the recent two months but without nausea, vomiting or seizures. Neurological examinations and full blood examination did not show abnormalities. A $3 \mathrm{~cm}^{*} 3 \mathrm{~cm}^{*} 2.5 \mathrm{~cm}$ cystic mass was detected 
by MRI in the left lateral ventricle with a homogeneous low signal intensity on T1WI and high signal intensity on T2WI (Fig. 1a and b), and hyperintense signals found on fluid-attenuated inversion recovery (FLAIR) (Fig. 1c) and in the diffusion-weighted image (DWI) (Fig. 1d). Mild wall and intracystic septation enhancement was observed after the administration of gadolinum diethylenetriamine pentaacetic acid (Gd-DTPA) (Fig. 1e).

\section{Treatment and results}

The patient underwent surgery for the removal of the cyst by the left temporal transcortical approach. After the left lateral ventricle was opened, a cystic lesion with a very thin wall was found, fluid inside the cyst was aspirated with a syringe following the puncture. A wide excision of the cyst and copious irrigation with saline was performed. However the cyst removal was incomplete due to its adhesion to the surrounding parenchyma. The remnant cystic wall was coagulated. On the postoperative day 1, axial T1-weighted MRI showed the subtotal resection of the cyst (Fig. 1f). The patient had headache and signs of meningeal irritation for 3 days after the surgery.

Cerebrospinal fluid (CSF) specimens were collected twice on postoperative day 3 and 5 by lumbar punctures and analyzed to exclude intracranial infection. Routine examination of CSFs showed that the number of nuclear cells was $20^{*} 10^{\wedge} 9 / \mathrm{L}$ on postoperative day 3 , and reduced to $10^{*} 10^{\wedge} 9$ on postoperative day 5 . None of RBCs were seen in the above examinations. Biochemical examination of the CSF displayed the protein content of CSF was $0.88 \mathrm{~g} / \mathrm{L}$, higher than the upper limit of normal level $(0.4 \mathrm{~g} / \mathrm{L})$. No abnormalities were found in cerebrospinal fluid culture.

Postoperative histopathological (hematoxylin and eosin staining) analysis of cystic wall specimen showed the pseudostratified ciliated columnar epithelium with a basement membrane (Fig. 2), confirming the diagonosis of NC.

The patient's headache was relieved after postoperative treatment and he was discharged 14 days after the surgery. A 2-month-later follow-up check showed no recurrence (Fig. 3).
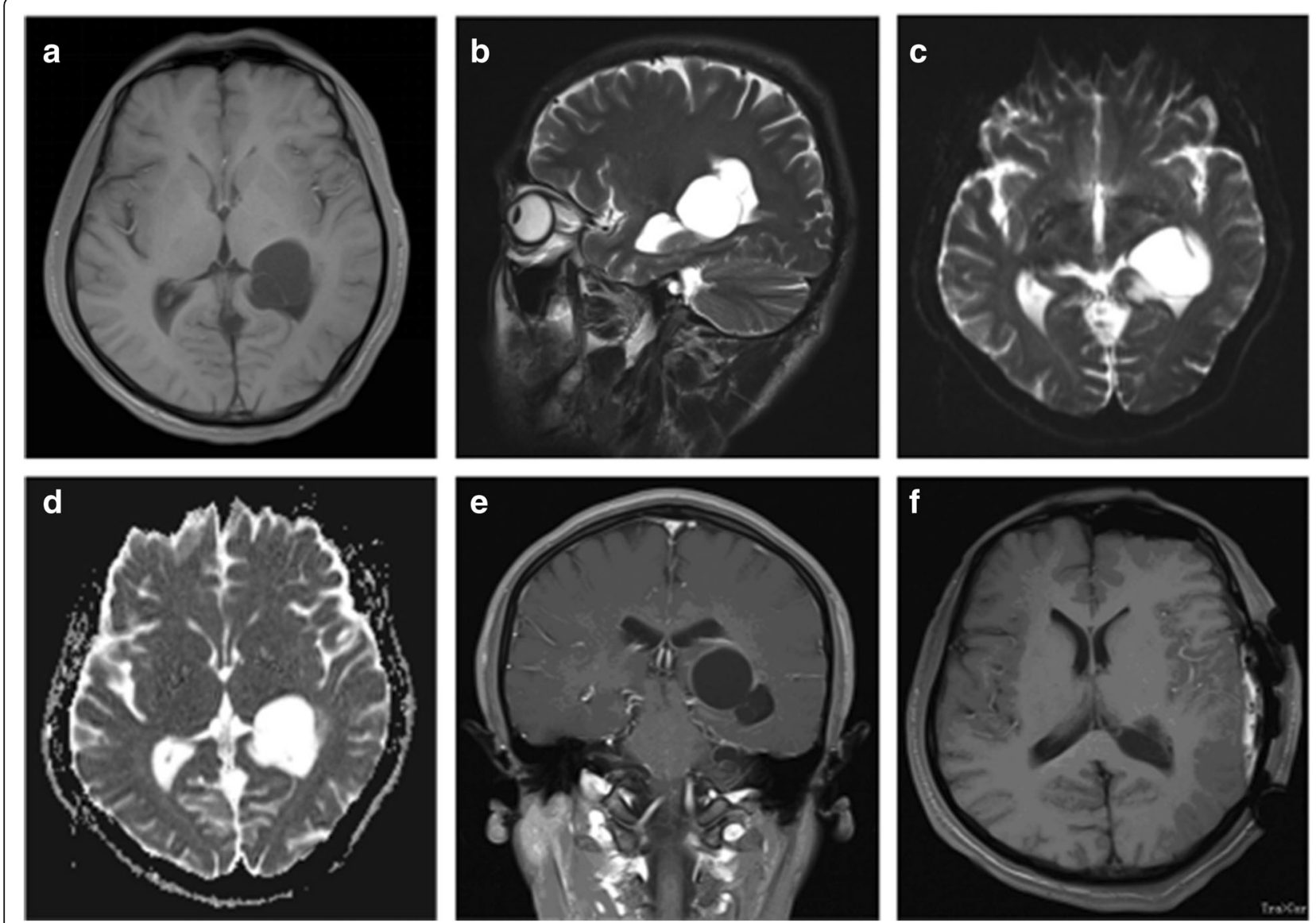

Fig. 1 Preoperative and postoperative images of the patient's brain. Preoperative axial T1-weighted MRI (a), sagittal T2-weighted MRI (b), axial fluid-attenuated inverion recovery(FLAIR) and axial diffusion-weighted image(DWI) showed a cystic lesion in the left lateral ventricle. (c, d), Preoperative coronal gadolinium-enhanced T1-weighted MRI scan showed mild capsule wall and septation enhancement after the administration of Gd-DTPA(e), The $1^{\text {st }}$ day of postoperative axial T1-weighted MRI showed subtotal resection of neuroenteric cyst(f) 


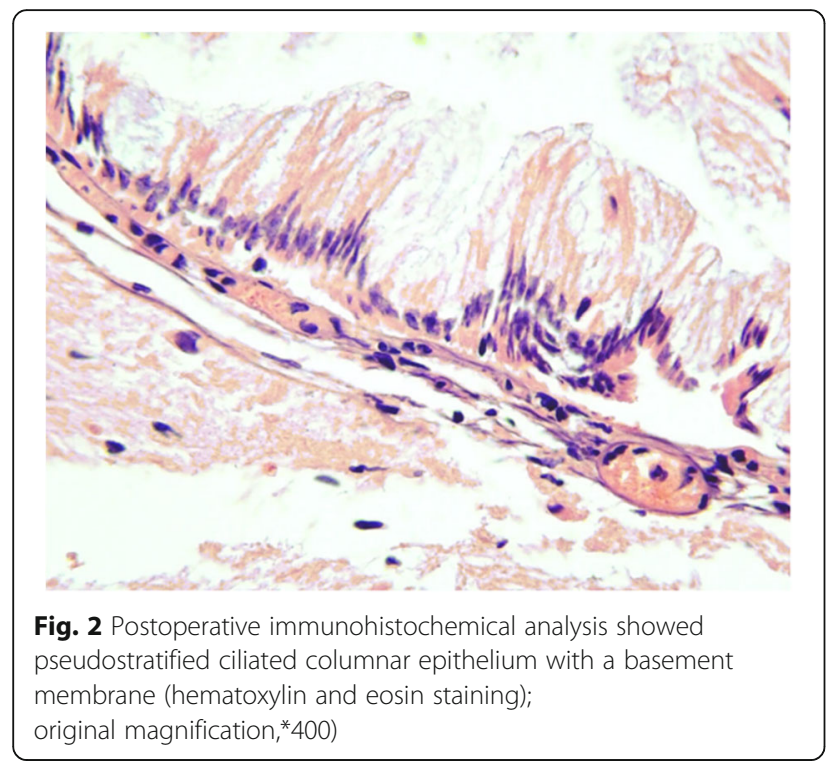

\section{Discussion}

$\mathrm{NC}$ is a kind of rare developmental anomaly and was first reported in 1934 [10] as an archenteric cyst of the cervical spinal cord. Because their pathogenesis has not been totally understood, historically this kind of lesions was named endodermal cyst, epithelial cyst, gastrocytoma, enteric cyst, foregut cyst, bronchogenic cyst, neurenteric cyst, enterogenous cyst, neuroenteric cyst and so on [2, 9, 11-13]. Although the World Health Organization preferred the term "enterogenous" in the revised classification of CNS

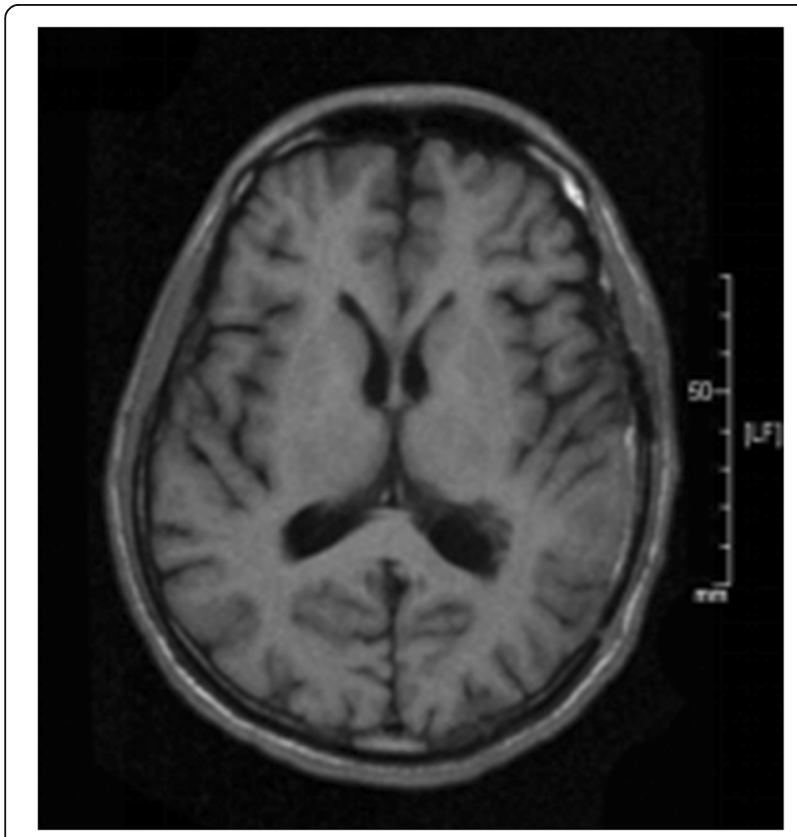

Fig. 3 Postoperative axial T1-weighted MRI of 2-month-follow-up showed no recurrence tumours [14], the term neuroenteric cyst has gained increasing support in the neuropathology literature [9].

\section{Epidemiological data of NCs}

Acording to the researches on epidemiology, the lower cervical and upper thoracic were the most common places, where NCs tended to develop ' 3 times more commom comapred with the brain [15]. Intracranial NCs were more scarce and approximately accounted for $0.15 \%$ of all intracranial neoplasms. In the reported cases of intracranial NCs, NCs mainly developed along the midline of the posterior cranial fossa, anterior to the brainstem or in the fourth ventricle $[8,12,16]$. In exceptional cases, multiple NCs in both the supratentorial and the infratentorial compartments have been documented $[2,11,13,17,18]$. There are 3 cases showed NCs in the supratentorial region [19-21], and 2 of these cases reported intramedullary lesions located in the cerebral hemisphere $[19,20]$. Intracranial $\mathrm{NCs}$ in the posterior fossa make up 70-90\% of all intracranial NCs cases [9]. We also found that intracranial NCs occurred more often at the age of the third and fourth decades. Preece et al reported a clear female predominance $(76.5 \%)$ in an intracranial NCs group [15]. However, Gauden and his colleagues found no significant gender preponderance [9]. The views on the effect of gender are still controversial.

\section{Development of NCs}

The pathogenesis of NCs is still not clear. The most confirmed hypothesis is that NC develops since the failure of the dissolution of the neuroenteric canal between the foregut or the respiratory buds and the notochord $[4,12,13,22]$. However, it cannot explain the origin of supratentorial NCs $[11,23]$. So, another theory was raised to explian where the supratentorial NCs came. The theory presumed that supratentorial NC might originate from a remnant of Seessel's pouch, which made up of endoderm that gives rise to the Rathke's pouch [23]. Based on the former hypotheis, the ectopic endodermal cells that travelled the furthest distance may lead to developing into dysplaisa or a malignant transformation, which could explian the diversity of the $\mathrm{NCs}^{\prime}$ loactions [24]. The pathogenesis of $\mathrm{NC}$ will be understood further with more cases of $\mathrm{NC}$, especially supratentorial $\mathrm{NC}$ being reported.

\section{Histopathological characteristics of NCs}

According to the literature, approximately $50 \%$ of the NCs were composed of gastrointestinal epithelium, 17\% were composed of ciliated respiratory epithelium and the reminder which is a mixed appearance of the gastrointestinal, respiratory, pancreatic and squamous epithelium $[25,26]$. NC walls usually were stained positive with anti-cytokeratin (CK), anti-epithelial membrane antigen (EMA) and anti-carcinoembryonic antigen (CEA) 
antibodies, suggesting an endodermal origin of the epithelium. As a result, light microscope examination and immunohistochemical analysis are the gold standards for the diagnosis of NC [9], which is basically characterized by cyst walls lined with simple or pseudostratified cuboidal or columnar epithelium, with a basement membrane, with or without cilia. Wilkins and Odom [27] classified NCs into three groups with what was described before as group A. Group B cyst was characterized by complex invaginations and associated glands producing mucinous or serous fluid in addition to Group A's structure. These cysts may contain the tissues of bone, cartilage, fat, nerve fibers, striated muscle, smooth muscle, lymphoid, elastic fibers, ganglion and Vater Pacini corpuscles. In addition to the features of Group B, Group C of NCs has ependymal or glial tissue.

In our case, immunohistochemical images of the NC only showed pseudostratified ciliated columnar epithelium with the basement membrane, suggesting the cyst found should be classified into Group A.

\section{Clinical features and differential diagnosis of NCs}

The clinical symptoms of NCs depend on their mass and location. [2, 4, 6, 13, 22, 28-30]. Clinical symptoms and signs of supratentorial NCs were greatly related to the increased intracranial pressure which led to the symptoms of headache, nausea and vomiting. Focal and generalized seizures with focal motor and sensory deficits were also observed in some NC patients [4, 18, 25, 31, 32]. Although the imaging characteristics and location of the cystic lesion might suggest the presence of the NC, they were not specific $[5,15]$. As a result, other intracranial cystic lesions, such as arachnoid, colloid, ependymal, epidermoid, dermoid and so on must also be considered in the differential diagnosis. Epidermoid and dermoid cysts usually grow with more irregular shape, often envelop neighboring vessels and nerves, more likely develope in nonmidline areas such as cerebellopontine angle (CPA). However, NCs grow expandingly rather than invasively with vessels and nerves surrounding usually displaced. In addition, dermoid cysts are usually hyperintensitive on both T1- and T2-weighted MRI. Intracranial NCs and arachnoid cysts have similar morphological features on imaging. But arachnoid cysts are isointense relative to CSF on all MRI sequences while NCs are quite variable, with their DWIs showing high signal intensity [33].

\section{NCs treatment and postoperative care}

Total surgical resection of the cyst wall is the ideal treatment of NCs at present [13,34,35]. However, in the case such as ours, a complete excision could not be performed due to the difficulty in separating the cystic wall from brain tissues without damaging the nervous structure. Unwanted parenchymal damage could lead to a high risk of neurological deficit. Therefore, a removal of cyst and its content as much as possible is suggested. Though incomplete excision of the cyst wall can relieve the symptoms immediately, recurrence may occur in the future. Small residual pieces of the cyst walls should be identified and coagulated to reduce the risk of recurrence [36].

Postoperative meningism has been reported with some patients complaining of headache, fever and neck stiffness after the surgery [36]. The patient in our case had headache deterioration but no fever postoperatively. Lumbar CSF specimen analysis showed protein content slightly increasing and negative result of CSF culture, and thus the diagnosis of aseptic meningitis was made. Regular lumbar punctures successfully relieved the symptoms. Aseptic meningitis is caused by leakage of cyst contents into the subarachnoid space. In order to prevent it, it was suggested to aspirate the fluid by the puncture, placing cotton patties surrounding the operative region before the resection and copious irrigation [36].

According to the literatures, the estimated time for a foreseeable recurrence after partial resection of NCs ranged between 2 months and 14 years [4]. Therefore a long-term clinical and neuroradiological monitoring of the patients is highly recommended. 2-month-follow-up check didn't show NC recurrence in our case. But longtime follow-up had been suggested strongly to the patient.

\section{Conclusion}

Intracranial supratentorial NCs are very rare and should be considered in the differential diagnosis of other types of cysts. Morphological analysis is essential in establishing a definitive diagnosis of NCs. The most effective therapeutic method at present is cystic content aspiration followed by complete cyst wall resection. But partial resection is an alternative since the risk of impairing normal surrounding structures should be minimized when the cyst wall is strongly adherent to the parenchyma.

Development and recurrence of NCs have not been studied thoroughly due to the limited case reports. Early diagnosis and more treatment options may be available in the future with more cases of NC being reported and its pathogenesis being understood further. We report the first case of the NC in the lateral ventricle, providing new evidence to develop the hypothesis on NC etiology.

\footnotetext{
Abbreviations

CEA: Anti-carcinoembryonic antigen; CK: Anti-cytokeratin; CNS: The central nervous system; CSF: Cerebrospinal fluid; DWI: Diffusion-weighted image; EMA: Anti-epithelial membrane antigen; FLAIR: Fluid-attenuated inversion recovery; Gd-DTPA: Gadolinum diethylenetriamine pentaacetic acid; MRI: Magnetic resonance imaging; NC: Neuroenteric cyst
}

\section{Acknowledgements}

This study was supported by Nanjing Medical Science and Technique Development Foundation, Nanjing Department of Health(No.QRX11197)(No.ZKX13035)(No.201308033). We thank Dr. Okada 
Yoshikazu (Tokyo Women's Medical University) and Dr. Kostadin L. Karagiozov (Tokyo Jikei University) for their suggestions in preparing this article.

\section{Funding}

Nanjing Medical Science and Technique Development Foundation.

\section{Authors' contributions}

Xiaoyang Ling and Shaofeng Yang carried out the clinical studies, participated in the follow-up and drafted the manuscript. Zhengxiang Luo carried out the immunoassays. Wenbing Zhang and Yansong Zhang participated in the operation and postoperative follow-up. Penglai Zhao conceived of the study, and participated in its design and coordination and helped to draft the manuscript. All authors read and approved the final manuscript.

\section{Competing interests}

The authors declare that they have no competing interests.

\section{Consent for publication}

The patient has consented to the submission of the case report for submission to the journal.

\section{Ethics approval and consent to participate}

The author daclare that all procedures in this case involving human participants were in accordance with the ethical standards of the institutional and/or national research committee and with the 1964 Helsink declaration and its later amendments or comparable ethical standards.

\section{Author details}

'Department of Neurosurgery, Nanjing Brain Hospital Affiliated to Nanjing Medical University, Nanjing 210029, China. ${ }^{2}$ Department of Neurosurgery, The Second People's Hospital of Taizhou, Taizhou 225500, China. ${ }^{3}$ Department of Neurosurgery, Lishui Peoples's Hospital, Nanjing 211200, China.

\section{Received: 10 June 2016 Accepted: 8 December 2016}

\section{Published online: 06 February 2017}

\section{References}

1. Zulch KJ. Histological typing of tumours of the central nervous system Geneva: World Health Organization; 1979. p. 21-59.

2. Krishnamurthy G, Roopesh Kumar VR, Rajeswaran R, et al. Supratentorial enterogenous cyst: a report of two cases and review of literature. Neurol India. 2010;58:774-7.

3. Büttner A, Winkler PA, Weis S. Endodermal cyst of the third ventricle: case report. Neurosurgery. 1997;40:832-5.

4. Perrini P, Rutherford SA, King AT, et al. Enterogenous cysts of the cerebellopontine angle: short review illustrated by two new patients. Acta Neurochir (Wien). 2008;150:177-84.

5. Osborn AG, Preece MT. Intracranial cysts: radiologic-patholgic correlation and imaging approach. Radiology. 2006:239:650-64.

6. Keating RF, Multani J, Cogen PH. Occult spinal dysraphism and the tethered spinal cord. In: Winn RH, editor. Youmans neurological surgery. 5th ed. Philadelphia: WB Saunders; 2004. p. 3257-88.

7. Wang YM, Ma ZY, Luo SQ. Intraspinal enterogenous cyst in children. Chin J Neurosurg. 2002;18:119-22

8. Bejjani GK, Wright DC, Scheseel D, Sekhar LN. Endodermal cysts of the posterior fossa:Report of three cases and review of the literature. J Neurosurg. 1998:89:326-35.

9. Gauden AJ, Khurana VG, Tsui AE, et al. Intracranial neuroenteric cysts: a concise review including an illustrative patient. J Clin Neurosci. 2012;19:352-9.

10. Puussepp M. Variete rare de teratome sous-dural dela region cervicale (intestinome). quadriplegie-extirpation:guerison complete. Rev Neurol. 1934;2:879-86.

11. Rangarajan V, Mahore A, Patil MK, et al. Supratentorial endodermal cysts Report of two cases. Asian J Neurosurg. 2016;11(3):310.

12. Kulkarni V, Daniel RT, Haran RP. Extradural endodermal cyst of posterior fossa: case report, review of the literature, and embryogenesis. Neurosurgery. 2000:47:764-7.

13. Christov C, Chretien F, Brugieres P, et al. Giant supratentorial enterogenous cyst: report of a case, literature review, and discussion of pathogenesis. Neurosurgery. 2004;54:759-63.
14. Kleihues P, Burger PC, Scheithauer BW. Histological typing of tumors of the central nervous system: World Health Organization. Berlin: Springer-Verlag; 1993.

15. Preece MT, Osborn AG, Chin SS, Smirniotopoulos JG. Intracranial neurenteric cysts: imaging and pathology spectrum. AJNR. 2006;27(6):1211-6.

16. Liu KJ, Couldwell WT. Far-lateral transcondylar approach: surgical technique and its application in neurenteric cysts of the cervicomedullary junction. Neurosurg Focus. 2005;19(2):E9.

17. Perry A, Scheithauer BW, Zaias BW, Minassian HV. Aggressive enterogenous cyst with extensive craniospinal spread: case report. Neurosurgery. 1999:44:401-4.

18. Kachur E, Ang LC, Megyesi JF. Intraparenchymal supratentorial neurenteric cyst. Can J Neurol Sci. 2004:31:412-6.

19. Okabe H, Katsura K, Yamano T, Tenjin H, Nakahara Y, Ishida M, Kato T. Mucinous adenocarcinoma arising from supratentorial intramedullary neuroenteric cyst with broncho-pulmonary ifferentiation. Neuropathology. 2014:34:420-4

20. Dunham CP, Curry B, Hamilton M. Malignant transformation of an intraaxialsupratentorial neurenteric cyst - case report and review of the literature. Clin Neuropathol. 2009;28:460-6.

21. Ho LC, Olivi A, Cho CH, Burger PC. Simeone F and Tihan T:Welldifferentiated papillary adenocarcinoma arising in a supratentoria enterogenous cyst: Case report. Neurosurgery. 1998;43:1474-7.

22. Akaishi $K$, Hongo K, Ito M, Tanaka Y, Tada T, Kobayashi S. Endodermal cyst in the cerebellopontine angle with immunohistochemical reactivity for CA 19-9. Clin Neuropathol. 2000:19:296-9.

23. Graziani N, Dufour H, Figarella-Branger D, et al. Do the suprasellar neurenteric cyst, the rathke cleft cyst and the colloid cyst constitute a same entity? Acta Neurochir (Wien). 1995;133:174-80.

24. Yang Y, Fang J, Li DA, Wang L, Ji N, Zhang J. Recurrent intracranial neurenteric cyst with malignant transformation: a case report and literature review. Oncol Lett. 2016;11(5):3395-402.

25. Basheer N, Kasliwal MK, Suri A, et al. Lateral extradural, supratentorial neurenteric cyst. J Clin Neurosci. 2010;17:639-41.

26. Fujita T, Kayama T, Saito $\mathrm{S}$, et al. Immunohistochemical detection of tumor marker in recurrent clivus enterogenous cyst - case report. Neurol Med Chir (Tokyo). 1997:37:479-82.

27. Wilkins RH, Odom GL. Spinal intradural cysts. In: Handbook of Clinical Neurology. New York: John Wiley \& Sons, Inc; 1976. p. 55-102.

28. Enynon-Lewis NJ, Kitchen N, Scaravilli F, Brookes GB. Neurenteric cyst of the cerebellopontine angle: case report. Neurosurgery. 1998;42:655-8.

29. Umezu H, Aiba T, Unakami M. Enterogenous cyst of the cerebellopontine angle cistern: case report. Neurosurgery. 1991;28:462-6.

30. Mishra GP, Sharma RR, Musa MM, et al. Endodermal cyst of septum pellucidum and pregnancy: a case report. Surg Neurol. 2000;53:583-5.

31. Tan GS, Hortobagyi T, Al-Sarraj S, et al. Intracranial laterally based supratentorial neurenteric cyst. Br J Radiol. 2004;77:963-5.

32. Neckrysh S, Valyi-Nagy T, Charbel FT. Neuroenteric cyst of the anterior cranial fossa: case report and review of the literature. Surg Neurol. 2006;65:174-7.

33. Shin JH, Byun BJ, Kim DW, Choi DL. Neurenteric cyst in the cerebellopontine angle with xanthogranulomatous changes: serial MR findings with pathologic correlation. AJNR. 2002;23:663-5.

34. Lee SH, Dante SJ, Simeone FA, Curtis MT. Thoracic neurenteric cyst in an adult: case report. Neurosurgery. 1999:45:1239-42.

35. De Oliveira RS, Cinalli G, Roujeau T, et al. Neurenteric cysts in children: 16 consecutive cases and review of the literature. J Neurosurg. 2005;103:512-23.

36. Wang $L$, Zhang J, Wu Z, et al. Diagnosis and management of adult intracranial neurenteric cysts. Neurosurgery. 2011;68:44-52.

\section{Submit your next manuscript to BioMed Central and we will help you at every step:}

- We accept pre-submission inquiries

- Our selector tool helps you to find the most relevant journal

- We provide round the clock customer support

- Convenient online submission

- Thorough peer review

- Inclusion in PubMed and all major indexing services

- Maximum visibility for your research

Submit your manuscript at www.biomedcentral.com/submit
Biomed Central 